\title{
At the Other End of the Phonograph
}

\author{
How Science and Humor Blend in the Work of the Phonographic Recording Laboratory \\ By Austin C. Lescarboura
}

A CCORDING to the textbook on physics, sound A follows certain definite rules. An hour's reading should give the average man a good grounding in the subject. Yet the truth of the matter is that it requires more than any amount of reading to acquire a practical understanding of sound phenomena; for sound waves, it appears, have a way of playing numerous and inexplicable tricks at almost any time, upsetting the calculations of even experts. So it follows that any business which is based on the commercializing of sound must be an interesting one because of these uncertainties and such indeed is the phonograph industry, wherein sound is captured or "canned," so to speak, and dispensed far and wide in the familiar form of records.

\section{"Atmosphere" and the Recording Studio}

In the very midst of the theatrical section of New York city is located the laboratory recently visited by the writer, for the purpose of studying a new process of making phonograph records. It was neither an office building nor a factory which bore the address he had set out to find; instead, it was an attractive four-story building with a white front trimmed with red-brick window-sill and arches ar arches and numerous window boxes filled to overflowing with intents it was a reside
of the better sort.

And the interior conveys the same impression to the visitor. For the reception room, which is reached directly from the street, is furnished with handsome rugs, tapestried furniture and floor-lamps, blending in a beautiful color scheme that is both pleasing and reassuring. pleasing and reassuring mercial about this reception room, which might as well serve as the living room of any well-to-do New Yorker. Then there are the private sitting rooms upstairs, furnished in the same furnished in the vided with grand pianos, vided with grand pianos, where artists can rehearse their selections before going to the laboratory proper.

The reader must pardon the seeming digression from the main thread of the story. However, the excuse is a good one in this case. All of the description just given goes to convey some idea of the "atmosphe" of studio and the high ideals of an organization ideals of an organization
which is perhaps the which is perhaps the
largest manufacturer of musical instruments in the world, and which only recently decided to enter into the manufacture of records in order to round out its phonograph enterprise. The organization had been producing a good phonograph; but, working on the theory that the phonograph and the but, working on the theory that the phonograph and the
record form an individual unit, it set to work producing records particularly suited to its machine.

Now this "atmosphere" matter appears to be an important one. There is such a thing as "phonograph fright," just as there is the well-known stage fright Some artists can go right into the laboratory and rake a perfect record from the very first; while others, cqually famed and talented, go up before the little sound hor only to succumb to an attack of phonograph fright This, no doubt, is due to the changed conditions; ther are no footlights, no audience, and no applause. Ther is simply a little $\cdot$ horn to stare at and to sing into. It is a brand new kind of work for the artist, who must learn to sing or play for the records. And that is where the "atmosphere" helps matters; for it removes much of the cold, mechanical aspect of recording. The artist comes to a "studio," not a factory; and in the seclusion of the home-like private sitting rooms he can rehearse his selections until he is ready for the laboratory on the floor above.

A long and wide room which has rounded corners only is the recording laboratory proper. At the farther end of this room is a partition with two doors, belind which is the delicate recording apparatus connected with the horn out front. All music is directed against this partition, in the center of which is the adjustable horn and as in the motion-picture studio, there is an interesting collection of equipment about the room ranging from chairs of all sizes and platforms of all heights to the bulkier of the musical instruments.

Presently the musicians, the singer, and the orchestra leader take their places facing the partition, for the purpose of recording a popular selection. The arrangement of the musicians proves to be a highly scientific one; in fact, the recording of each instrument being known through long experience, it is accordingly assigned to a place either nearer or farther away from the signed to a place either nearer or farther away from the
horn. The singer is directly in front of the horn and quite close to it, so that tha voice will be predominant on the record. The orchestra leader stands on a platform to the side of the horn, in plain view of everyone. The most bizarre feature of this laboratory scene is, no doubt, the seating arrangement. In order that each instrument will "focus" on the horn without interference of any sort, the musicians are seated on chairs of varying of any sort, the musicians are seated on chairs of varying
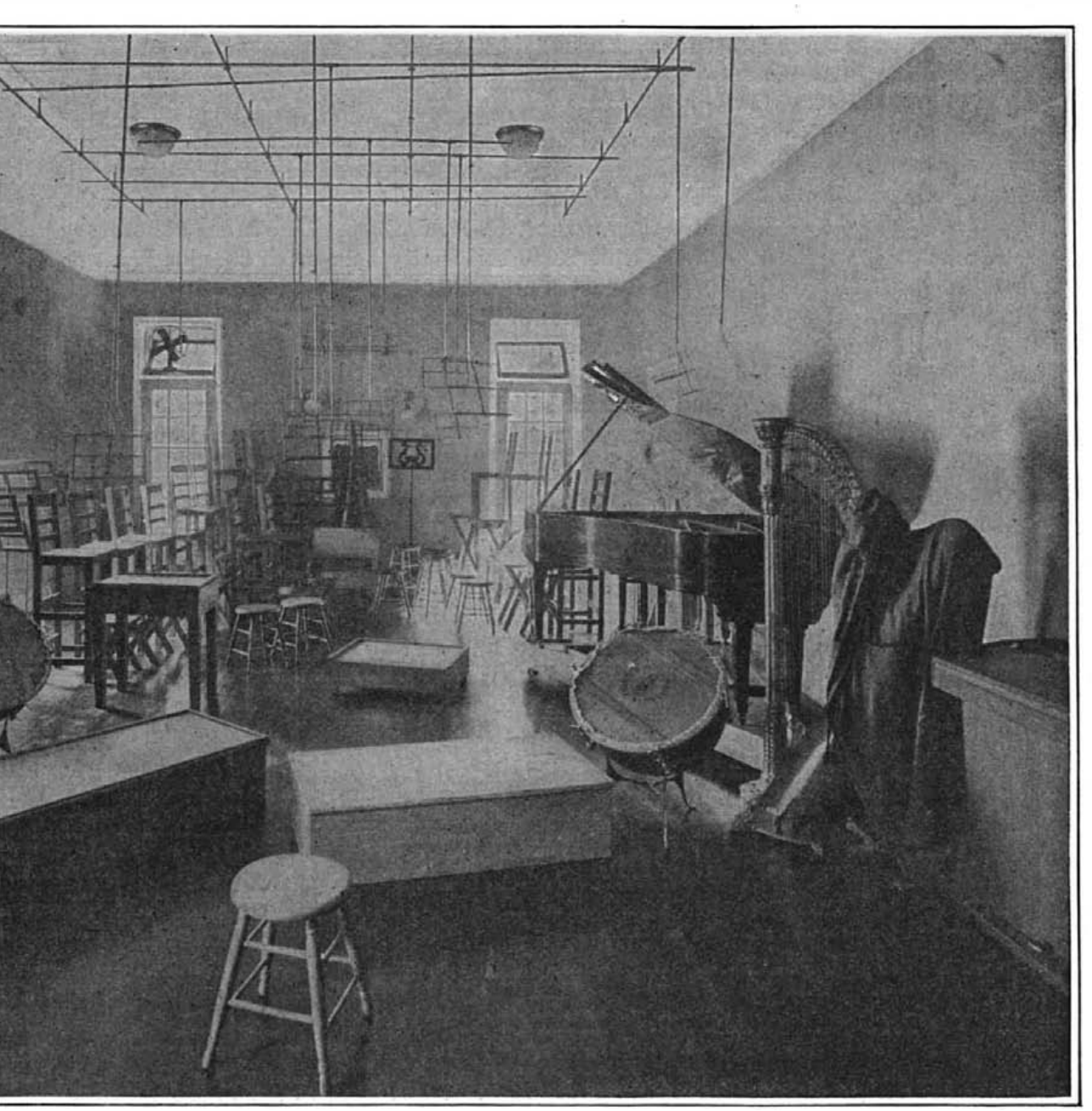

concert. The lady artists having no shirt sleeves to roll up and collars to remove, work in what amounts to as much, namely, in shirtwaist and skirt or other plain but comfortable clothes, instead of the evening gowns of the concert stage.

When everything is in readiness, the musicians wait for the buzzer signal which indicates that the recording apparatus has started and that every sound is being recorded. With the sound of the first buzzer signal, silence reigns.

A few seconds later a second buzzer signal indicates that the selection can begin, since the requisite number of blank grooves have been cut at the start of the record. It is these blank grooves which permit the turntable of the home phonograph to come to speed before the selection begins.

In the confined room of the recording laboratory the selection sounds quite loud. The leader carefully coaches the artist as well as the musicians. Finally, when the last note is reached, singer and musicians stop short without another sound until a voice from the other side of the partition announces the completion of the record. Because of the automatic stopping devices now so common on phonocraphs, several blank grooves must cut at the end of the record as well as at the beginning, and these grooves must of course be silent. undred Per Cent

Should there be a discordant note during the recording of a selection, the wax record is irreparably ruined and work must start all over again. There is no such thing as patching in the recording process: the rendition must be absolutely correct before the record is considered usable. Once in a great while it so happens that a singer or a musician struggles unsuccessfully with a sneeze or cough that refuses to be downed. Right in the middle of a wonderful selection a sneeze or
cough breaks out triumphantly! And no matter how much time may have been expended on the record up to that point, it is now wasted and work must begin all over again on a fresh wax disk

What takes place during the recording of a selection can best be learned by entering the long and narrow room back of the partition, back of the partition,
which, to be sure, is a which, to be sure, is a
great and rare privilege;

heights, with the lowest ones nearest the horn and the highest ones-six feet tall, in some cases-at the rear of the semi-circle. The music stands, in turn, are suspended from the ceiling, by an arrangement of overhead rails and hangers.

Certain instruments, such as horns, must be kept in the background, while others, the violin for instance, are placed in the front row. In the case of brass instruments where the horn is behind the player, a queer situation arises. The sound must be directed toward the horn yet the musician must follow the orchestra leader. But these factors are apparently irrelevant. Fortunately, however, there are such things as mirrors; and with a large mirror mounted on an adjustable stand, the musician can sit.with his back to the horn and the leader, while observing both through the mirror in front of him. Hence it is evident that appearances count little in the phonographic laboratory; sound and sound only is the vital thing.

The dress of the musicians also carries out the impression that appearances are secondary to results. Comfort being the first requisite to results, utmost comfort is therefore the rule. The musicians and the artist work in their shirt sleeves if they prefer, rather than in full dress and other decorum of the theatre and for every phonograph
company considers its recording apparatus as the very
heart and brain of the organization. It is a true "holy heart and brain of the organization. It is a true "holy holies." And why should 't it be? a " mects and years of experience and found in such little ment are centered on the apparatus found in such little
rooms as this one, or at the small end of the recording horn.

Now the sound waves entering the large end of the specially devised horn are brought down and intensified as they approach the smaller end. Here they strike upon a diaphragm which vibrates in response to their impulses. Connected with the center of this diaphragm by a delicate lever is a fine cutting tool. This tool, moving in response to the motion of the diaphragm cuts a groove in a revolving disk of soft wax, which groove corresponds in configuration with the outline of the sound waves entering the horn.

The wax disk rests on a turntable operated by a gravity motor. Before each recording the weights of the gravity motor are raised to the ceiling of the room, so that there will be no danger of a stop during the subsequent run. Electric motor, spring motor, or any other form of drive is certain to fluctuate slightly in speed no matter what precautions may be taken; but gravity (Concluded on page 178) 

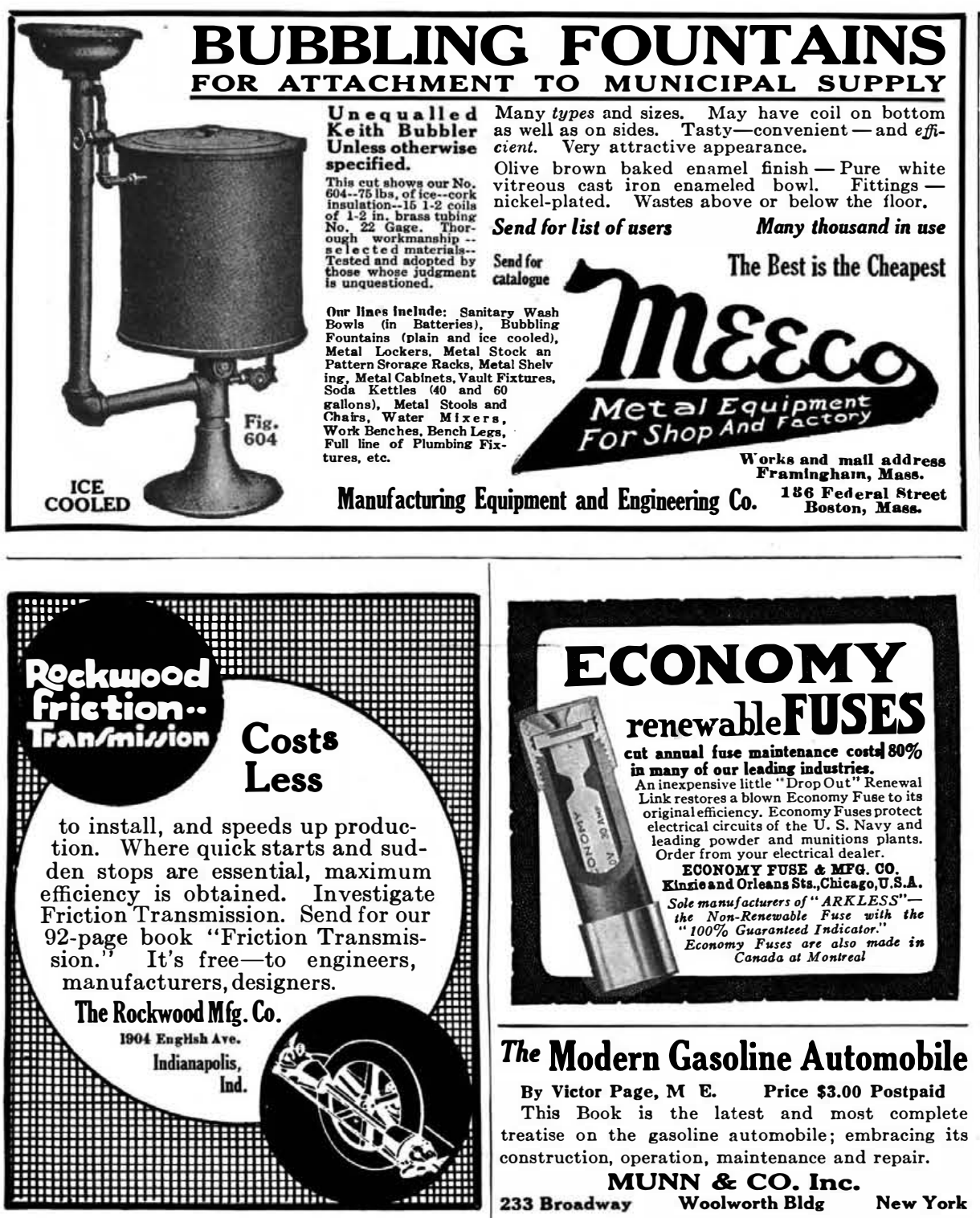

The Modern Gasoline Automobile

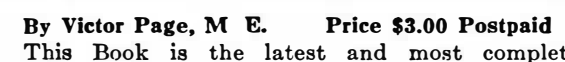
This Book is the latest and most comple
tratise on the gasoline automobile; embracing it 233 Broadway WUN \& \& CO. IInc.
Wootworth Bldg

\section{How the Allies lost Constantinople- Ambassador Morgenthau's amazing story of the greatest blunder of the} war.

\section{Henry Ford tells why he wants to go to the Senate and why a pacifist is now fighting.}

Germany's secret trade plots, an astounding plan as revealed by. Herzog, the trade Bernhardi.

Read all of these compelling articles and as many more in the September

\section{WORLD'SWORK}

The subscription price will be advanced to $\$ 4.00$ a year on September 10th. Until then you may subscribe for one or two years at $\$ 3.00$ a year. The price per copy is $35 c$. It is expected that Federal regulations will put magazines on a non-returnable basis, restricting their distribution. This offer gives you an opportunity to subscribe to the WORLD'S WORK at the old rate and thus make sure of it for a year or two. It is one of the few essential magazines for these times. The new rates are effective in a few days-use the convenient coupon or write a letter, if you would take advantage of the $\$ 3.00$ rate.

THE WORLD'S WORK, Garden City, New York

I enclose........ f for..... . years, subscription to THE WORLD'S WORK at the special rate of $\$ 3.00$ a year.

Name

Address
At the Other End of the Phonograph (Concluded from page 164)

is a constant force and a gravity motor can be relied upon to maintain a definite speed. The recorder, in turn, is moved across the face of the disk by a lon threaded shaft with which it engages; and by using various threads the number of grooves cut to the inch can be varied. In this instance the record is of the up-anddown or so-called "hill and dale" cut, Packman process of recording is employed permitting of a large number of grooves to the inch.

Much depends on the wax disk. It surface is carefully prepared so as to be absolutely flat and smooth and free from imperfections of any kind. Preparatory to being used, the wax disks are kept in a cabinet that is electrically heated so as a selection is to be recorded, the wax disk, measuring a half inch or more in thickness by the usual diameter of the standard record, is placed on the turntable. The gravity motor is started and the producer tool placed the proper distance in from the edge. The buzzer signal is given to the orchestra leader at this time, and with the cutting of the required number of blank grooves the second or "start" signal i given.

- This part of the work is in charge of a recording expert who has been in the original Edison tinfoil records. As the record is being cut the recorder examines the grooves with a powerful magnifying glass so as to make sure that they are being properly formed. All the while a stream of air is blowing on the cutting tool so as to disengage the wax shavings, while A stop watch on the wall indicates the playing time of the record being made, which is checked up with the time limit set beforehand.

\section{Checking Up the Test Record}

The first wax record is a so-called test record. At the time the writer was in the recording room, Madame Easton of the completed a well-known operatic selection for the test record, when she entered the recording room, in company with the musical director and several musicians.

In a few moments the recording staff had substituted a reproducer with a small tin horn for the recording member, and the selection was being repeated in miniature, so to speak. Madame Easton and the staff, pressed close to the tiny horn so as not to lose a single note. Meanwhile the director, with the musical score in his hands, followed the selection. Here he pointed out a loud note which had to be subdued; at another point he pointed out the weakness of the accompaniment; at tion of a word, and so on. Indeed, he was "reading" that record, just as the editor proofreads and revises this page before the reader ever sees it.

Then the little group filed out of the recording room back to their places on the other side of the partition; and a few minutes later the selection was again bein

Surely, the recorder in charge of the wo should know something about sound waves. He had been capturing and "canning" them for the past three decades or more. Here was an authority who could tell us something about sound. Yet in answer to the writer's question he gave this startling reply: "I know practically nothing about sound: Every day I come across some new peculiarity; and it is only by constantly watching out for the tricks
of sound waves and meeting them with of sound waves and meeting them with
counter-tricks that we make good records!" Still, this gentleman can tell us some-
then thing about those tricks which he has encountered and countered. He explains how some instruments reproduce better than others. The violoncello is a veritable trouble maker, so it seems: in orchestrations it is generally replaced by some brass instrument that approximates its deep, large numbers for the phonographs of the vibrant notes. Yet in solos the violon- world. cello goes well. The piano is a poor reproducer alone or in company; in fact is excellent.

When it comes to making up an orchestra or band for a record, the known recording properties of the instruments are the guiding consideration, and the ensemble i arranged accordingly. Indeed, there is a limit to the size of an orchestra or band for recording purposes, beyond which no additional effects are produced. In fact, interference is apt to set in. For acnot exceed eight or ten players for giving the effect of a large theatre orchestra, provided each instrument is in the hand a talented musician.

All of which goes to say that orchestras and bands for recording purposes and for propositions.

Eloctrotyping at Its Highest Development After the wax record is completed, the wax is allowed to set or become hard. The test record is thrown out after having served its purpose, for the reason that the grooves of soft wax have been more or less ruined by the steel needle of the reproducer. In the instance of the accepted master record, there is no telling how
sounds until it has passed through the various processes leading up to the first olded record.

The wax master is carefully covered ove with fine powdered graphite, which is hollow. It is then into every groove and plating tank and subjected to a weak electric current for a period of 45 to 50 hours. The weak current necessitates long immersion in the plating bath, and the deposit, in consequence, is extremely fine grained. The thin shell of coppe deposited on the graphited wax, carrying every groove and variation of the master, is stripped from its support and soldered on a heavy brass disk, after which it is nickel plated to harden its surface. This electrotype, to give it the proper name, the "master."

A second electrotype operation now follows. The nickel-plated master is treated pla acid to prevent the next coppe an electrotyping tank for a period of 50 hours. The thin copper shell is then removed and mounted on metal, and the electrotype thus obtained is called th "mother." The mother is nickel-plated, treated with acid, and placed in the toctroplating tank in order to produce as the "matrix" and from which the comercial records are molded.

So from the wax record to the finished product there are the master, mother, and the matrix electrotypes. Should anything happen to the matrix, a new one can be made from the mother; and should anything befall the matrix and the mother the process can be restarted from the
master, which is kept in the vaults of the organization.

Every step in electrotyping must be record is no better than the poorest work (the weakest link) of any department. types, starting at one end of a groove and tracing it over hill and dale some half mile or more to the very end, armed with powerful magnifying glass and an engraver's tool. Little burrs and other slight imperfections of electrotyping are while, however, due care must be taken to remove or damage the "music" at the bottom of the groove. Electrotypes are delicately polished on high-speed spindles with soft rags and cleaning liquids. Inspections with magnifi

The ultimate product of this studio is the sample record which is molded from the matrix When this sample or When this sample or fle it is perhaps the poorest of all, and is carefully done, for like a chain the finished 